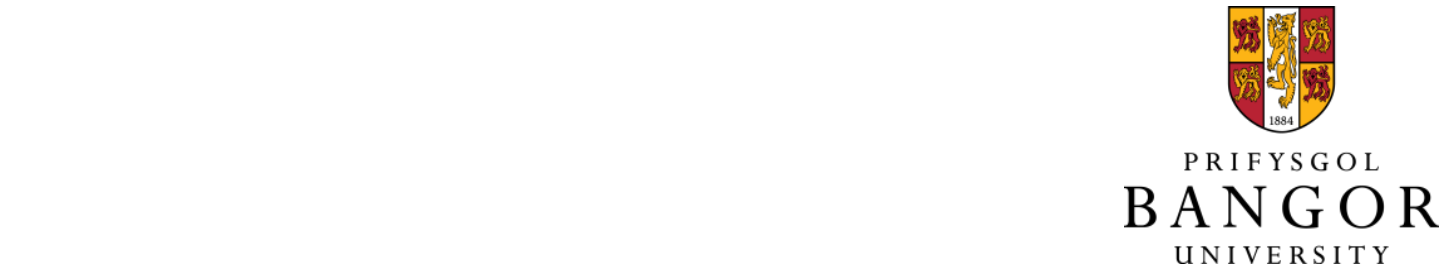

Persistent and context-dependent effects of the larval feeding environment on post-metamorphic performance through the adult stage

Torres, G.; Gimenez, L.; Pettersen, A.K.; Bue, M.; Burrows, M.T.; Jenkins, S.R.

\title{
Marine Ecology Progress Series
}

DOI:

$10.3354 /$ meps 11586

Published: 08/03/2016

Peer reviewed version

Cyswllt i'r cyhoeddiad / Link to publication

Dyfyniad o'r fersiwn a gyhoeddwyd / Citation for published version (APA):

Torres, G., Gimenez, L., Pettersen, A. K., Bue, M., Burrows, M. T., \& Jenkins, S. R. (2016).

Persistent and context-dependent effects of the larval feeding environment on post-metamorphic performance through the adult stage. Marine Ecology Progress Series, 545, 147-160.

https://doi.org/10.3354/meps11586

\footnotetext{
Hawliau Cyffredinol / General rights

Copyright and moral rights for the publications made accessible in the public portal are retained by the authors and/or other copyright owners and it is a condition of accessing publications that users recognise and abide by the legal requirements associated with these rights. study or research.

download and print one copy of any publication from the public portal for the purpose of private

- You may not further distribute the material or use it for any profit-making activity or commercial gain

- You may freely distribute the URL identifying the publication in the public portal ?
}

Take down policy

If you believe that this document breaches copyright please contact us providing details, and we will remove access to the work immediately and investigate your claim. 
2

7

8

9

10

11

12

13

14

15

16

17

18

19

20

21

22

23

24

25

26

PERSISTENT AND CONTEXT-DEPENDENT EFFECTS OF THE LARVAL FEEDING ENVIRONMENT ON POST-METAMORPHIC PERFORMANCE THROUGH TO THE ADULT STAGE

(1)

(1)

(1)

Torres Gabriela, Giménez Luis, Pettersen Amanda Kate, Bue Mathilde, Burrows Michael (1) Timothy, Jenkins Stuart Rees 
One of the central issues in ecology is the identification of processes affecting the population structure and dynamics of species with complex life cycles. In such species, variation in both the number of larvae that enter a population and their phenotype are important drivers of survival and growth after metamorphosis. Larval experience can have strong effects on key post-metamorphic traits but the temporal scale of such "trait-mediated effects" may be short and their magnitude may depend on the environment experienced after metamorphosis. We used an intertidal barnacle to study the long-term consequences of traitmediated effects under different post-metamorphic conditions by manipulating larval food concentration and monitoring patterns of survival and growth in juveniles at two intertidal levels over a 5 month period. In two replicated experiments higher food levels resulted in increased body size, mass and reserves (measured from elemental composition) in the settling larval stage and increased body size of newly metamorphosed juveniles. In Experiment 1 high food concentration reduced juvenile mortality at low intertidal levels while on the upper intertidal, mortality was high for all larval food concentrations. By contrast, in Experiment 2 low larval food concentration decreased juvenile survival at both shore levels. When present, effects were established early (weeks 1 or 2) and persisted for over 10 weeks in Experiment 1 and 22 weeks in Experiment 2. Interactive effects of the larval and juvenile environments can have important implications for population size: trait-mediated effects may persist for long periods contributing to explain patterns of adult abundance.

Keywords: benthic invertebrate, food limitation, larval environment, trait-mediated effect, recruitment 
For species with complex life cycles, a better understanding of processes affecting the structure and dynamics of populations and communities is achieved if studies consider both pre- and post-metamorphic stages (Thorson 1950, Grosberg \& Levitan 1992, Caley et al. 1996, Jenkins 2005, Allen \& Marshall 2010, Marshall \& Morgan 2011). In marine invertebrates, the number of individuals successfully settling and metamorphosing, as well as the patterns of recruitment, can vary enormously over a number of spatial and temporal scales (e.g. Jenkins et al. 2000, Navarrete et al. 2002, Broitman et al. 2008); in barnacles such variation has been attributed to patterns of predation (Gaines \& Roughgarden 1987), behaviour (Jenkins 2005) and transport by currents (Roughgarden et al. 1988). While for many decades benthic ecologists focused on post-settlement processes to explain patterns of community structure, the discovery of the role of the pre-settlement processes changed the views about the organization of marine communities, which now recognises the balance between the role of pre- and post-metamorphic processes operating on cohort dynamics (Connell 1985, Gaines \& Roughgarden 1985, Menge 2000, Jenkins et al. 2008). At a wider scale the consideration of pre-settlement processes on connectivity, has contributed to the development of the field of marine metapopulation dynamics (Armsworth 2002, Shima \& Swearer 2009). In addition, a growing body of work has also shown that the environmental conditions experienced by larval stages can affect the phenotype and eventually the performance and survival after metamorphosis (Prout \& McChesney 1985, Giménez 2004, Pechenik 2006, Aguila et al. 2013). These effects called "trait-mediated effects" (Giménez 2004, Kerby et al. 2012), are part of a wider type of plastic response where traits of organisms are altered in response to biotic and abiotic pressures (Miner et al. 2005); these effects are widespread among organisms, and have important consequences for the organization of communities (Schmitz et al. 2003, Werner \& Peacor 2003, Ohgushi et al. 2012).

The most widely studied type of trait-mediated effect is perhaps that operating top-down, where morphological or behavioural traits of a consumer are modified by the presence of predators (Kerby et al. 2012); in tri-trophic food chains, the response of the consumer to predator cues can modify the abundance of the producer. There are also bottom-up effects where, for instance, food availability or the physical environment experienced by early (e.g. larval) stages affect physiological or morphological traits of advanced stages, and subsequently their chances of survival, and recruitment (Giménez 2004, Pechenik 2006). 
Here, the emphasis is on the consequences of modified traits as they propagate through the life cycle. We know that the larval environment can have a profound influence on individual size and available reserves at the time of metamorphosis. A range of studies have clearly demonstrated that over the first days of post-metamorphic life the larval environment can determine metamorphic success (e.g. Tremblay et al. 2007), survival (Pechenik et al. 1993) and the ability to tolerate food limitation (Thiyagarajan et al. 2003 a, b) or physical stress (Phillips 2002). However, we still do not clearly understand the long term consequences of trait-mediated effects propagating through the life cycle, for instance if effects of early (e.g. larval) experience will reach beyond a few days after metamorphosis. Strong effects, i.e. those that can influence population dynamics, should have long-term consequences on fecundity or on the number of individuals reaching reproductive maturity. The strength of such effects may be restricted to species with a short post-metamorphic phase. In species with a short juvenile phase ( $<4$ weeks) the larval environment can affect fecundity (Prout \&McChesney 1985, Wendt 1998); extreme cases are the holometabolous insects where feeding larvae eclose into an adult stage whose energy reserves largely depend on larval history (Aguila et al. 2013).

In addition, environmental conditions experienced after metamorphosis modify the strength of a trait-mediated effect leading to context-dependent effects. For instance, environmental stochasticity, experienced at advanced stages, may also limit the strength of trait-mediated effects because it may blur the relationship between the larval environment, post-metamorphic phenotype and survival. In species with long post-metamorphic phases (months to years), laboratory studies where environmental conditions are kept constant, show that effects of larval experience on phenotype are still found ca. three months after metamorphosis (Giménez et al. 2004, Giménez 2010). However, relationships between early and late phenotypes are sometimes weak in the wild (Lindholm et al. 2006, Auer et al. 2010), where conditions in the post-metamorphic environment can re-shape phenotypes (and modify fitness) or produce immediate effects on mortality, irrespective of the phenotype.

Context-dependent effects are important even in the absence of environmental stochasticity but the lack of research (Allen \& Marshall 2013) still precludes the formulation of specific predictions about which environmental contexts enable trait mediated effects to influence recruitment. While some studies have shown trait-mediated effects when postmetamorphic conditions are harsh (Spight 1976, McGinley et al. 1987, Hutchings 1991, Tamate \& Maekawa 2000, Phillips 2002, Allen \& Marshall 2013), the opposite pattern has 
also been reported (Moran \& Emlet 2001). Most likely, contradictory results reflect different type of stressors (Moran 1999) or non-linear responses to a stressor (Allen et al. 2008): i.e. the fact that under extremely harsh conditions all organisms die irrespective of traits, while in benign conditions trait-mediated advantages are too small. In the first case, some specific stressors may select for particular body sizes, while other stressors may not (Moran 1999). In the latter case, trait-mediated effects may arise if environmental conditions are intermediate between the extremes described above (Allen et al. 2008). More complex responses that have been found in field studies evaluating larval responses to egg size and thermal conditions, i.e. across another life history boundary, suggest that complex patterns are possible. For example in the frog Bombina orientalis larvae hatching from large eggs perform better at low temperatures or under low variability in temperature but the patterns reverse at high temperatures (Kaplan 1992, Kaplan \& Phillips 2006).

In marine benthic invertebrates, observations suggest mortality is generally high throughout a range of taxa over the period following metamorphosis (Gosselin \& Qian 1997, Hunt \& Scheibling 1997, Underwood \& Keough 2001, Gosselin \& Jones 2010). However, mortality at advanced juvenile stages can also be high if intraspecific competition increases as individuals use more resources (Jenkins et al. 2008, Giménez \& Jenkins 2013), and modelling output indicates that juvenile/adult survival is critical to local dynamics (Svensson et al. 2004). These results suggest that a longer term perspective of trait mediated effects, integrating across life stages, is required.

In this paper we address the questions of the long term consequences of trait mediated effects under different post-metamorphic contexts. We studied the effect of larval food environment on larval quality and subsequent long term post-metamorphic survival and growth of an intertidal acorn barnacle in two habitats characterised by different levels of environmental stress over a period of 22-25 weeks. The study addressed the following questions: (1) What is the relationship between the larval environment and the phenotype before and after metamorphosis? (2) Do we see trait-mediated effects? (3) Do these traitmediated effects propagate through time or alternatively does stochastic variation override the signal? (4) If present, do trait-mediated effects depend on the environmental context (tidal elevation)? 
The model species

Intertidal barnacles are a useful model system to address trait-mediated effects on population dynamics. They develop through a series of pelagic larval feeding stages, the nauplius, followed by a non-feeding larval stage, the cyprid, which settles and metamorphoses. Food conditions experienced by nauplius stages determine the amount of reserves available to the cyprids to search for an appropriate settlement site and undergo metamorphosis (West \& Costlow 1987, Hentschel \& Emlet 2000, Thiyagarajan et al. 2003 a, b). Metamorphosis requires a considerable amount of total available reserves (e.g. 30\% in Semibalanus balanoides: Lucas et al. 1979) and feeding does not start until 2-5 days after metamorphosis (Rainbow \& Walker 1977). Hence it is not surprising that both laboratory (Thiyagarajan et al. 2003a) and short term field studies (Jarrett 2003, Tremblay et al. 2007) have found that metamorphic success and early post-metamorphic survival are influenced by the larval food environment and positively correlate with the amount of cyprid reserves (Jarrett \& Pechenik 1997, Miron et al. 1999). However, the long term effects of the larval environment and how this interacts with levels of post larval environmental stress are not known.

Austrominius modestus, a non-native species originally from Australasia, was first recorded in the UK in 1945 (Crisp 1958) and since then it has spread rapidly throughout the European continent (Harms 1986). The duration of larval development, through six naupliar stages followed by the cyprid, depends on temperature: in the Irish Sea, larvae are expected to take ca. 15 days (Harms 1999) to reach the first juvenile stage. In the study area, larval development and settlement takes place mainly during the summer through to early autumn. Juveniles feed on plankton at high tide, grow rapidly and are able to breed within 12 weeks (Crisp \& Davies 1955).

Adult Austrominius modestus were collected from the mid intertidal zone of Menai Bridge (Isle of Anglesey, UK), and maintained in the laboratory in seawater. In two separate experiments, in September and October 2011, larval release was stimulated by detaching the adults from the rock. For each experiment freshly hatched larvae, from ca. 100 adults, were pooled and then divided among 1851 vessels. Nauplii were mass-reared at an initial density 
of 0.8-1.0 individual per $\mathrm{ml}$ at three different food concentrations (6 replicate vessels per food treatment) using the diatom Skeletonema costatum as food (Harms 1987). Larvae were reared following Harms (1987) at low $\left(1 \times 10^{5}\right.$ cells $\left.\mathrm{ml}^{-1}\right)$, medium $\left(2 \times 10^{5}\right.$ cells ml ${ }^{-1)}$ and high $\left(3 \times 10^{5}\right.$ cells $\mathrm{ml}^{-1}$ ) food concentrations at $16^{\circ} \mathrm{C}$ under gentle aeration. These concentrations produced low larval mortalities in preliminary experiments. Water and food were changed every second day and dead larvae discarded. Towards the end of each experiment, water was changed daily and cultures were inspected for cyprids. When cyprids amounted to $50-80 \%$ of larvae present (in most cases ca. 24-48 h from when the first cyprids were observed) the contents of each culture vessel were transferred to a separate settlement vessel made of PVC, each containing 6 natural slate tiles of $3 \times 3 \mathrm{~cm}$ each (i.e. there was a settlement vessel associated to each replicate culture vessel). After 48 hours, tiles with settlers were out-planted to the field and remaining swimming cyprids discarded, to avoid confounding food treatment effects with effects of delayed metamorphosis. Development time to reach the cyprid stage varied slightly among food treatments such that transfer to the settlement vessel and subsequent settlement was delayed by one and two days in intermediate and low food concentrations respectively compared to high food. Rather than maintain settlers from different food treatments under lab conditions for differing periods, out-planting was performed at the end of the settlement period and hence out-plant dates differed by a maximum of 2 days among food treatments. Most tiles (90\%) had densities below 5 ind ${ }^{*} \mathrm{~cm}^{-}$ 2; the maximum density of settlers per tiles was $93\left(\sim 10\right.$ ind $\left.{ }^{*} \mathrm{~cm}^{-2}\right)$; density did not vary in any consistent way among food treatments. Observations showed that settled individuals were unlikely to compete for space or resources since there was enough free space between settlers until the end of the experiment. Therefore food effects were not confounded with density effects.

Tiles were out-planted (Experiment 1: 21-23 Sept 2011; Experiment 2: 17-19 Oct 2011) on a rocky intertidal outcrop under the suspension bridge in the Menai Strait (ca. $800 \mathrm{~m}$ from the laboratory) at two tidal levels, $4.8 \mathrm{~m}$ and $3.0 \mathrm{~m}$ above Chart Datum, corresponding to the upper and lower distribution of Austrominius modestus. Three PVC frames were used at each tidal level and tiles (2 to 3 from each vessel) were attached using a $5 \mathrm{~mm}$ pre-drilled hole through the tile centre at random across these frames. In total between 100 and 400 individuals were out-planted per treatment combination.

All tiles were photographed, to determine survival and growth rates, before out-planting and then at bi-weekly (weeks 2-10) intervals, and at the end of the experiments in March 
2012 (Experiment 1: 25 weeks and Experiment 2: 22 weeks). In addition, in Experiment 2, tiles were also sampled one week after out-planting. During the first two weeks, tiles were photographed under a dissecting microscope (Leica Microscope MZ 6) by transporting tiles, attached to the PVC frames, to the laboratory during low tide, and returning before the incoming tide. Subsequently, barnacle sizes were large enough to allow appropriate estimations of body size through in situ photography (Pentax Optio W60 camera mounted on a PVC frame). Digital images were processed using Image $\mathrm{J}$ software; all surviving individuals were counted and the basal and operculum length measured in 5 individuals from each replicate settlement vessel. Body size measurements ended when less than 5 individuals per replicate vessel remained on the tiles (week 10 for Experiment 1 and week 22 for Experiment 2).

\section{$\underline{\text { Body size, dry mass and elemental composition of swimming cyprids }}$}

In both experiments cyprid body size was determined by measuring 20 cyprids per replicate vessel under the microscope; cyprids were collected as swimming individuals within the first $48 \mathrm{~h}$ of the first cyprids being observed. In Experiment 2, dry mass and elemental composition were also determined by sampling 100 swimming cyprids from each replicate vessel. Sample processing followed Anger \& Harms (1990): 100 individual cyprids were pipetted out of each replicate vessel, quickly rinsed in distilled water, blotted dry with filter paper, placed in aluminium cartridges and frozen at $-20^{\circ} \mathrm{C}$ for later analysis; 20 randomly chosen individuals per sample were measured under the microscope before being placed in the cartridges. Samples were freeze-dried (Edwards Supermodulyo $12 \mathrm{k}$ freeze-drier) and weighed using a microbalance (Mettler Toledo, precision $=1 \mu \mathrm{g}$ ). Elemental composition (Carbon and Nitrogen content) was determined using a CHNS-O Analyser (Thermo Electron Flash EA 1112 Series).

\section{$\underline{\text { Statistical analysis }}$}

We used each culture vessel, and corresponding settlement vessel, as a replicate unit, such that all tiles originating from each vessel were considered as one replicate. A minimum of five vessels from each food treatment produced suitable tiles. Statistical tests were run for each experiment separately. We first tested if food concentration affected cyprid body size, dry mass or elemental carbon and nitrogen content. For body size we obtained data from individual cyprids: therefore, a nested ANOVA was used with food concentration as a fixed factor and culture vessel nested within food concentration (replicate unit = individual larvae 
sampled from within each vessel). A one-way ANOVA was used for dry mass and elemental composition where one sample per vessel (made up of 100 cyprids) was obtained. After significant differences in ANOVA, differences among treatments were tested here and in subsequent analyses using SNK posthoc tests.

We tested if the body size of metamorphs (basal and operculum length) varied between intertidal level and larval food using a two-way ANOVA. Our analyses confirmed that body size did not differ among intertidal levels at the time of out-planting (see results).

The effects of larval food concentration, intertidal level and time on survival were tested through a 3-way repeated measures ANOVA using each of the settlement vessels as our replicate unit (i.e. values from tiles within each settlement vessel were combined). Variances were homogeneous (Cochran's test) and residuals did not show any serious deviations from the normal distribution.

Since the highest mortality rates were observed during the first 2 weeks (see results), we also tested for potential effects of initial densities of post-metamorphs on the proportion of barnacles surviving the first 2 weeks in the intertidal. This test considered interactions of initial barnacle numbers, larval food and intertidal level and was made using tiles (instead of vessels) as this was the natural replicate unit to express densities. Tests were run using general least square (gls function in nlme package: Pinheiro 2015) using the VarPower constructor function (variance depended on barnacle density). Pearson residuals showed homogeneity and did not show serious deviations from normal.

The effects of larval food concentration, intertidal level and time on body size of metamorphs (basal and operculum length) were tested using Generalized Linear Modelling (GzLM) with Gamma distribution and logarithmic link function. ANOVA was not used because variances were heterogeneous and did not follow a normal distribution even after data transformation.

\section{RESULTS}

$\underline{\text { Effect of food concentration levels on traits of swimming cyprids and metamorphs }}$ 

length (Table 1), with low food concentration resulting in a 4 to $7 \%$ reduction in size compared with those from the high food level. Intermediate food concentrations resulted in cyprid lengths equivalent to the high food treatment in Experiment 1 but an intermediate size in Experiment 2 (Fig. 1).

Dry mass (DW) and elemental composition were only measured in Experiment 2. At low food concentrations cyprid DW was $41 \%$ lower than at intermediate and high food levels (Table 2: significant food effect, Fig. 2a). Significantly lower carbon (C) and nitrogen (N) content per individual were also found under low food levels (data not shown). The amount of carbon per individual cyprid, for example, was $47 \%$ lower at low food concentrations compared to high. Levels of $\mathrm{C}$ and $\mathrm{N}$ relative to DW also responded to food treatments: \% $\mathrm{C}$ was significantly greater in the high food treatment with $9.5 \%$ and $7 \%$ lower values in low and intermediate food treatments respectively (Table 2, Fig 2b). In contrast to all other patterns $\% \mathrm{~N}$ was highest in the low food treatment, and significantly lower in the mid and high treatments (11-13\% lower than in high food treatment, Fig. 2c). The strong food effects on $\mathrm{C}$ compared to $\mathrm{N}$ led to significant differences in $\mathrm{C}: \mathrm{N}$ ratio among all treatments (high to mid to low food); in larvae reared under low food concentrations this ratio was $21 \%$ lower than in those reared under the highest food concentration (Fig. 2d).

At the time of out-planting, body size (basal and operculum length) of metamorphs (within 24hs. of metamorphosis) varied among food concentrations but not between intertidal levels (Table 3, Fig. 3) showing that individuals of different sizes were effectively allocated randomly among intertidal levels. In both experiments, the highest food concentration resulted in the largest basal length after metamorphosis (Fig. 3 a-b). Low food concentration resulted in metamorphs that were 15\% (Exp-1) and 8\% smaller (Exp-2) in basal length than those from high food concentration. The operculum length was largest for individuals metamorphosed from larvae reared under high food concentrations in Experiment 1 (Fig. 3c), but similar sizes were found between individuals reared under high and medium food concentrations in Experiment 2 (Fig. 3d).

It is interesting to note in Experiment 1 the way in which cyprid size responded differently to food treatments than metamorph size (Fig 1a vs. Fig 3a). The medium food concentration produced cyprids equivalent in body length to those at high food concentrations. However, this size advantage over the low food treatment was not maintained in metamorphs, where the 
medium food concentration clearly produced metamorphs equivalent to those from low food with a basal and opercular length on average $16 \%$ and $13 \%$ respectively, smaller than in the high food treatment.

\section{$\underline{\text { Post-metamorphic survival }}$}

In both experiments the percentage of out-planted barnacles surviving to a specific week (cumulative survival) decreased strongly during the first 2 weeks and then remained steady over the study period (Fig. 4). In Experiment 1 (Fig. 4 a-b), the effect of larval food environment on cumulative survival depended on intertidal level (Table 4, significant 2-way interactions). Significant effects of larval food concentration were restricted to the lower intertidal: high larval food concentrations resulted in the highest survival; the differences between low and intermediate food concentrations were not significant. This effect of food on survival on the lower intertidal was established between the time of out-planting and week 2 $(06 / 10 / 11)$. On average $65 \%$ of metamorphs originated from the high food level survived the first two weeks after out-planting; only $37-46 \%$ of those from the intermediate and low food level survived that period (Fig. 4a, SNK posthoc tests). By contrast, in the upper intertidal survival was low irrespective of the larval food treatment (on average $25 \%$ of the out-planted metamorphs, Fig. 4b).

Further examination of Experiment 1 shows that the effect of food observed in the low intertidal at week 2, remained (except in week 6) until week 10 (Fig. 4a, SNK posthoc test) owing to a bi-weekly survival (percentage surviving any two-week period) which was consistently high (>70\%) irrespective of food treatment. By week 10 the cumulative survival was on average $37 \%$ in juveniles metamorphosed from larvae reared at high food concentrations, significantly higher than those at intermediate and low food concentrations which showed an average survival of 15 and 24\%, respectively (Fig. 4a). At week 25 $(16 / 03 / 12)$ the effect of larval food concentration on cumulative survival was not significant, but the trend was still present (Fig 4a). The loss of significance was most likely due to loss of power in the test since very few individuals ( $<5$ per tile), remained alive at that time. In summary, in Experiment 1, the effect of larval food on barnacle density, found in the low intertidal level, was established in the first two weeks; these differences in barnacle density due to the effect of larval food were maintained from week 2 until week 10.

In Experiment 2 there was a significant main effect of larval food concentration which was consistent across both intertidal levels (Table 4); cumulative survival was lowest in 
metamorphs which originated from the lowest food concentrations while those from intermediate and high food concentration showed similar levels of survival (Fig. 4 c-d, SNK posthoc test). In this experiment the effect of larval food conditions on survival was apparent one week (24/10/11) after settlement and these differences remained over the whole 22 week study period. The percentage survival after two weeks was on average $34 \%$ for the metamorphs from the low food level and $52 \%$ for those from high and intermediate food levels. After the second week, bi-weekly survival was high (on average $>80 \%$ ) irrespective of food treatment. Thus, the differences in barnacle density related to larval food environment, were established during the first two weeks and remained for 22 weeks of the study period.

Examination of survival as a function of density revealed inconsistent patterns. For Experiment 1, initial density (D) and proportion of survivors (S) after 2 weeks were weakly but negatively correlated $(S=0.48-0.0022 \mathrm{D}, \mathrm{p}=0.016)$ irrespective of the food and intertidal level. For Experiment 2, the correlation of initial density and survival depended on the intertidal level: for the high level the correlation was positive $(S=0.54+0.0025 \mathrm{D}, \mathrm{p}=$ 0.04), and for the low level, the correlation was not significant; again.

\section{$\underline{\text { Post-metamorphic growth }}$}

Overall, barnacles grew from ca. 0.55 to $4-5 \mathrm{~mm}$ in basal length (Fig. 5) and from 0.39 to 1.5-2.5 $\mathrm{mm}$ in operculum length (data not shown). In Experiment 1, the effect of food concentration was found only in the lower intertidal (intertidal level $\mathrm{x}$ food interaction: Table 5): high food concentration led to significantly larger body size on the lower intertidal, (basal length, Fig. 5a) and operculum length (not shown) than the intermediate and lower food concentrations (SNK posthoc test). These differences were established at the time of outplanting (see Fig. 3 for details) and appeared to increase with time (Fig.5a). Initially the basal length of metamorphs from the low and intermediate food treatments were on average 0.12 $\mathrm{mm}$ smaller than those from the high food treatment $(0.55 \mathrm{vs} 0.67 \mathrm{~mm})$; this difference increased to $1 \mathrm{~mm}$ after 10 weeks. By contrast, proportional differences varied little between the time of out-planting (17\%) and after 10 weeks (19\%). There was no effect of food treatment on growth in Experiment 2. 
In species with complex life cycles, spatial and temporal variation in the timing of metamorphosis can be important in determining the structure and dynamics of populations and communities (Gaines \& Roughgarden 1985, Caley et al. 1996, Connolly et al. 2001, Jenkins et al. 2008) and metapopulation persistence (Armsworth 2002). However, recent work shows that variations in traits (e.g. body size, nutritional reserves), at or after metamorphosis, also affect subsequent survival or reproduction (Pechenik 2006) and can translate into effects on recruitment (Giménez 2004) and reproductive potential for a population (Burgess \& Marshall 2011). Such trait-mediated effects may be strong in species with a short post-metamorphic phase. However, it is not straightforward to expect similar effects for species with longer post-metamorphic life (Pechenik et al. 1998) because postmetamorphic conditions (i.e. stochasticity, biotic interactions, stress, disturbance or densitydependent effects) may prevail over any effect produced by the pre-metamorphic environment. Using an intertidal barnacle as a model we found: (1) that effects of the larval environment on performance, when present, had long term consequences, affecting the abundance and size of individuals reaching reproductive maturity; (2) context-dependent effects of the larval environment on performance, mediated by changes of larval and postmetamorphic traits. In addition, we found: (3) variable responses among experiments that may reflect variations in the environmental context or other sources (e.g. genotype $\mathrm{x}$ environment interactions). Long-term but variable effects (context-dependent or not) add to the complex ways in which trait-mediated effects can affect natural communities (Werner \& Peacor 2003, Ohgushi et al. 2012).

The persistence of trait-mediated effects is critical in demonstrating that larval traits can have a strong influence on population level processes. We showed persistence of effects from the time of settlement in autumn until the spring (an age at which A. modestus can be reproductively mature: Crisp \& Davies 1955). Most studies demonstrating effects of larval history on performance, focus on the first 2-3 weeks after metamorphosis (Pechenik et al. 1993, Phillips 2002, Thiyagarajan et al. 2003 a, b). Temporal persistence of larval effects is not widely known for marine invertebrates (but see Allen et al. 2008) and we are not aware of any field study tracking cohorts of invertebrates for several months after manipulating the larval environment. Previous studies, in species with short maturation times, have shown important effects of the larval environment on adult cohorts (e.g. Prout \& McChesney 1985; Wendt 1998) or effects of the natal habitat on population dynamics over several generations (Van Allen \& Rudolf 2013). Our results extend those carried out with short post metamorphic 
phases and point to the potentially widespread effect of the larval environment on recruitment. There is now an important body of work that highlights the contributory role of oceanographic conditions in determining the recruitment of individuals to adult stages, through effects on larval settlement (Connolly et al 2001). In addition, variations in oceanographic conditions leading to, for example, changes in food availability, may also contribute to changes in recruitment through modifications of traits at or after metamorphosis.

During our study, it was striking to observe that patterns in survival, once established, persisted over a long period irrespective of biotic and abiotic processes operating after metamorphosis. These patterns were established during the first two weeks when mortality in invertebrate juveniles is known to be particularly high (Gosselin \& Qian 1997, Hunt \& Scheibling 1997, Underwood \& Keough 2001, Gosselin \& Jones 2010); on average, 58\% of the out-planted juveniles were lost during that period. In the case of barnacles, the level of reserves at metamorphosis is critical since for the following few days they cannot feed (Rainbow \& Walker 1977); therefore, it is likely that there is a critical window where effects of larval experience on post-metamorphic survival are highest.

A potential process leading to high early mortality is density-dependence, for instance competition. In our case however, density-dependence did not seem to be an overall explanation for the high mortality observed in both experiments. Significant negative correlations between densities and survival were found only in Experiment 1. Competition was unlikely because metamorphs were distributed randomly over the plates, at low densities (max. density $=10$ ind $\mathrm{cm}^{-2}$ ), at such distances that they would not have opportunity to engage in competition. A previous study on barnacle density-dependence carried out also on Welsh intertidal shores, albeit on Semibalanus balanoides (Jenkins et al. 2008), suggest that such process requires higher densities (above $20 \mathrm{ind}^{*} \mathrm{~cm}^{-2}$ ) for 1 month old juveniles that are larger and occupy more space than 2 week old Autrominius modestus.

Patterns established early in the benthic phase persisted because actual mortality rates did not vary further among food treatments (only 16\% were lost in any subsequent 2 week period) leading to the so called type III trajectory (Caley 1998). We can only speculate about the reasons behind the maintenance of the patterns. The timing of our experiments meant that surviving juveniles developed through autumn-winter conditions when low temperatures may reduce the strength of biotic interactions or metabolic requirements. Perhaps the timing of 
settlement in relation to the seasonality in the environment is an important factor determining the extent of trait-mediated effects. In addition, a reduction in sensitivity to environmental conditions through ontogeny could also be important (McCormick \& Hoey 2004).

It is important to understand the physiological mechanisms leading to trait-mediated effects to progress toward a predictive theoretical framework. In this particular case, the mechanisms leading to trait-mediated effects may involve processes occurring before, during and after metamorphosis. First, low larval food concentration resulted in a reduction in cyprid size, \% C content and body mass (DW) as well as a reduced $\mathrm{C}: \mathrm{N}$ ratio, effects which are consistent with findings for other barnacles (Thiyagarajan et al. 2002 b, Emlet \& Sadro 2006); most of the changes in $\mathrm{C}$ content may result from reductions in the proportion of total lipids or triacylglycerols, which have been linked with variations in growth and survival of early barnacle stages (Thiyagarajan et al. 2002 a, b; Tremblay et al. 2007). Second, important changes appeared to occur during metamorphosis because differences in body size among larval food treatments were not fully equivalent between pre-metamorphic (cyprid) and postmetamorphic juvenile stages. For example, in Experiment 1 intermediate levels of food produced larger cyprids which were equivalent in size to the high food treatments, but metamorphs that were smaller and equivalent to individuals raised on low food concentration; a similar mis-match occurred in Experiment 2. In addition, examination of standardised average values of cyprid and metamorph size and early survival show clearly that survival was fully linked to metamorph, but not cyprid size (Supplementary figure). Overall, these findings emphasise the importance of the interaction between physiological processes determining larval traits and the process of metamorphosis in establishing early postmetamorphic traits, which appeared to underpin the patterns of survival.

Another important result was the context-dependent nature of the trait-mediated effects. In Experiment 1, the effects of larval environment on survival were only evident in the lower intertidal; in the upper intertidal, where conditions are expected to be more stressful (longer daily periods of desiccation, extreme temperatures and lower food supply) survival was strongly depressed, irrespective of food quality. Most related studies argue that the benefits of better quality larval phenotype will be expressed in poorer quality environments (e.g. Spight 1976, McGinley et al. 1987, Hutchings 1991, Tamate \& Maekawa 2000, Phillips 2002, Allen $\&$ Marshall 2013) yet our work did not show this. Observations similar to our own have been made by Moran \& Emlet (2001) who showed that hatching size of the gastropod Nucella ostrina positively affected early survival in a benign shaded habitat but not in a stressful sun- 
exposed environment. It is likely that under the conditions tested in our first experiment, the feeding/desiccation conditions were too harsh in the upper intertidal, but not in the lower intertidal. The limited number of studies and contradictory results still precludes making any generalization about how variations in traits of metamorphs affect recruitment along the intertidal gradient.

The still limited capacity for generalization is further shown by our results from the second experiment, where trait-mediated effects were found at both levels; this is relevant as a warning for interpreting results of studies lacking any level of repetition. We can only speculate that either environmental variability or variability among cohorts of settling larvae may drive trait-mediated effects. Evidence in favour of an environmental effect, in particular thermal stress, comes from naturally occurring differences in temperature experienced by juveniles out-planted in the different experiments. Temperature records (Hilbre Island meteorological station) show that the average air temperature during the first two weeks after the out-planting in September $\left(17.8^{\circ} \mathrm{C}\right.$, ) was five degrees higher than in that experienced by barnacles out-planted in October $\left(13.2^{\circ} \mathrm{C}\right)$; during the same period, daily temperature maxima (September: $25^{\circ} \mathrm{C}$; October: $<20^{\circ} \mathrm{C}$ ) coincided with midday/early afternoon low water periods. These data, combined with the laboratory observations of Foster (1971) of 50\% mortality rates of $A$. modestus recruits at $20^{\circ} \mathrm{C}$, suggest that high intertidal level out-plants in Experiment 1, where larval food treatment effects were not observed, would have been exposed to potentially much higher levels of emersion stress than those in Experiment 2, where trait-mediated effects were clear. An alternative view of our results is that the different outcomes of the two experiments may reflect variations in larval phenotypes among cohorts. Evidence in favour of this hypothesis is that the effect of the larval food concentration on basal and operculum diameter was weaker in the cohort out-planted in October than that outplanted in September; hence, that cohort would have been better suited to tolerate the conditions existing in the upper intertidal level. Variations in phenotypes may reflect genetic variability or maternal effects on egg sizes and embryonic development. Variations in egg size within populations are important in intertidal barnacles in particular (Barnes \& Barnes 1965). Significant spatial and temporal variations in larval size at hatching among parents have been recorded recently for A. modestus in our study area (Griffith 2013), but we still do not know if these are carried over to the cyprid stage.

We conclude that trait-mediated effects can be important to understand the patterns of recruitment of organisms to the adult cohorts. Early effects of the larval environment on post- 
settlement survival can persist for months and eventually define number and quality of adults. Our data showed that this persistence was maintained through low levels of late juvenile mortality occurring over the winter. Specific trait responses are central to understand the nature of trait-mediated effects across gradients in thermal and nutritional stress. The key trait responsible for the patterns of survival appears to be the size at metamorphosis, which may affect the capacity to cope with food limitation or other stress during the first days of life. Such a trait was shaped at the time of metamorphosis and did not fully correlate with larval traits, which were also affected by larval nutritional conditions. We also conclude that traitmediated effects can be context-dependent but that such phenomena also depend on the level of habitat harshness or the variability among cohorts in the phenotypic responses to environmental conditions.

AKNOWLEDGEMENTS Special thanks are due to Dr. Katherine Griffiths for her help in rearing the microalgae. This research was funded by a Natural Environment Research Council (NERC) grant NEH006702/1 (UK), to SRJ, LG, MTB and GT.

\section{REFERENCES}

Aguila JR, Hoshizaki DK, Gibbs AG (2013) Contribution of larval nutrition to adult reproduction in Drosophila melanogaster. J Exp Biol 216(3):399-406

Allen RM, Marshall DJ (2010) The larval legacy: Cascading effects of recruit phenotype on ecological interactions. Oikos 119:977-1983

Allen RM, Marshall DJ (2013) Phenotypic links among life-history stages are complex and context-dependent in a marine invertebrate: interactions among offspring size, larval nutrition, and post-metamorphic density. Funct Ecol 27(6):1358-1366

Allen RM Buckley YM, Marshall DJ (2008) Offspring size plasticity in response to intraspecific competition: An adaptive maternal effect across life-history stages. Am Nat $171: 225-237$ 
532 Anger K, Harms J (1990) Elemental (CHN) and proximate biochemical composition of 533 decapod crustacean larvae. Comp Biochem Physiol B97:69-80

534 Armsworth PR (2002) Recruitment limitation, population regulation, and larval connectivity 535 in reef fish metapopulations. Ecology 83:1092-1104

536 Auer SK, Arendt JD, Chandramouli R, Reznick DN (2010) Juvenile compensatory growth 537 has negative consequences for reproduction in Trinidadian guppies (Poecilia reticulata). Ecol Lett 13:998-1007

Barnes H, Barnes M (1965) Egg size, nauplius size, and their variation with local, geographical and specific factors in some common cirripedes. J Anim Ecol 34:391-402

Broitman BR, Blanchette CA, Menge BA, Lubchenco J, Krenz C, Foley M, Raimondi PT, Lohse D, Gaines SD (2008) Spatial and temporal patterns of invertebrate recruitment along the West coast of the United States. Ecol Monogr 78:403-421

Burgess SC, Marshall DJ (2011) Are numbers enough? Colonizer phenotype and abundance interact to affect population dynamics. J Anim Ecol 80:681-687

Caley MJ (1998) Age-specific mortality rates in reef fishes: evidence and implications. Aust J Ecol 23:241-245

Caley MJ, Carr MH, Hixon MA, Hughes TP, Jones GP, Menge BA (1996) Recruitment and the local dynamics of open marine populations. Annu Rev Ecol Syst 27:477-500

Connell JH (1985) The consequences of variation in initial settlement vs. post-settlement mortality in rocky intertidal communities. J Exp Mar Biol Ecol 93(1):11-45

552 Connolly J, Menge BA, Roughgarden J (2001) A latitudinal gradient in recruitment of 553 intertidal invertebrates in the northeast Pacific Ocean. Ecology 82:1799-1813 
Crisp DJ, Davies PA (1955) Observations in vivo on the breeding of Elminius modestus 557 grown on glass slides. J Mar Biol Ass UK 34:357-380

558 Emlet RB, Sadro SS (2006) Linking stages of life history: How larval quality translates into 559 juvenile performance for an intertidal barnacle (Balanus glandula). Integr Comp Biol $560 \quad 46(3): 334-346$

561 Foster BA (1971) Desiccation as a factor in the intertidal zonation of barnacles. Mar Biol $8: 12-29$

Gaines S, Roughgarden J (1985) Larval settlement rate: A leading determinant of structure in an ecological community of the marine intertidal zone. P Natl Acad Sci 82(11):3707-3711

Gaines SD, Roughgarden J (1987). Fish in offshore kelp forests affect recruitment to intertidal barnacle populations. Science 235:479-481

567 Giménez L (2004) Marine community ecology: the importance of trait-mediated effects propagating through complex life cycles. Mar Ecol Prog Ser 283:303-310

Giménez L (2010) Relationships between habitat conditions, larval traits and juvenile performance in a marine invertebrate. Ecology 91:1401-1413

571 Giménez L, Jenkins SR (2013) Combining traits and density to model recruitment of sessile organisms. PLoS ONE 8(3):e57849

Giménez L, Anger K, Torres G (2004) Linking life history traits in successive phases of a complex life cycle: effects of larval biomass on early juvenile development in an estuarine crab Chasmagnathus granulata. Oikos 104:570-580

577

Gosselin LA, Jones LA (2010) Effects of solar radiation on barnacle settlement, early postsettlement mortality and community development in the intertidal zone. Mar Ecol Prog Ser 407:149-158

Gosselin LA, Qian P-Y (1997) Juvenile mortality in benthic marine invertebrates. Mar Ecol Prog Ser 146:265-282 
581 Griffith K (2013) Climate-driven changes in the recruitment success of marine invertebrates:

582 The role of food supply and temperature. PhD Dissertation, School of Ocean Sciences, 583 Bangor University, Bangor, UK

584 Grosberg RK, Levitan DR (1992) For adults only? Supply-side Ecology and the history of 585 larval biology. Trends Ecol Evol 7(4):130-133

586 Harms J (1986) Effects of temperature and salinity on larval development of Elminius 587 modestus (Crustacea, Cirripedia) from Helgoland (North Sea) and New Zealand. $588 \quad$ Helgolander Meeresunters 40:355-376

589 Harms J (1987) Energy budget for the larval development of Elminius modestus (Crustacea: 590 Cirripedia). Helgolander Meeresunters 41:45-67

591 Harms J (1999) The neozoan Elminius modestus Darwin (Crustacea, Cirripedia): Possible 592 explanations for its successful invasion in European water. Helgolander Meeresunters $52: 337-345$

Hentschel BT, Emlet RB (2000) Metamorphosis of barnacle nauplii: Effects of food variability and a comparison with amphibian models. Ecology 81:3495-3508

Hunt HL, Scheibling RE (1997) The role of early post-settlement mortality in recruitment of 597 benthic marine invertebrates. Mar Ecol Prog Ser 155:269-301

Hutchings JA (1991) Fitness consequences of variation in egg size and food abundance in brook trout Salvelinus fontinalis. Evolution 45:1162-1168

Jarrett JN (2003) Seasonal variation in larval condition and postsettlement performance of the barnacle Semibalanus balanoides. Ecology 84:384-90

Jarrett JN, Pechenik J (1997) Temporal variation in cyprid quality and juvenile growth 603 capacity for the barnacle Semibalanus balanoides. Ecology 78:1262-1265 and adult distribution in two chthamalid barnacles. J Anim Ecol 74:893-904 
606

607

608

609

610

611

612

613

614

615

616

617

618

619

620

621

622

623

624

625

626

627

628

629

630

Jenkins SR, Åberg P, Cervin G, Coleman RA, Delaney J, Della Santina P, Hawkins SJ, LaCroix E, Myers AA, Lindergarth M, Power A-M, Hartnoll RG (2000) Spatial and temporal variation in the settlement and recruitment of the intertidal barnacle Semibalanus balanoides (L.) (Crustacea: Cirripedia) over a European scale. J Exp Mar Biol Ecol 243:209-225

Jenkins SR, Murua J, Burrows MT (2008) Temporal changes in the strength of densitydependent mortality and growth in intertidal barnacles. J Anim Ecol 77:573-584

Kaplan RH (1992) Greater maternal investment can decrease offspring survival in the frog Bombina orientalis. Ecology 73:280-288

Kaplan RH, Phillips PC (2006) Ecological and developmental context of natural selection: maternal effects and thermally induced plasticity in the frog Bombina orientalis. Evolution 60:142-156

Kerby J, Wilmers CC, Post, E (2012) Climate change, phenology and the nature of consumerresource interactions: advancing the match-mismatch hypothesis. - In Ohgushi T. et al. (eds.) Trait-mediated indirect interactions. Cambridge University Press, pp 508-525

Lindholm AK, Hunt J, Brooks R (2006) Where do all the maternal effects go? Variation in offspring body size through ontogeny in the live-bearing fish Poecilia parae. Biol Lett 2:586-589

Lucas MI, Walker G, Holland DL, Crisp DJ (1979) An energy budget for the free-swimming and metamorphosing larvae of Balanus balanoides (Crustacea: Cirripedia). Mar Biol $55: 221-229$

McCormick M, Hoey, A (2004) Larval growth history determines juvenile growth and survival in a tropical marine fish. Oikos 106:225-242

McGinley MA, Temme DH, Geber MA (1987) Parental investment in offspring in variable environments: theoretical and empirical considerations. Am Nat 130:370-398 
631 Marshall DJ, Morgan SG (2011) Ecological and evolutionary consequences of linked life632 history stages in the sea. Curr Biol 21:R718-R725

Menge BA (2000) Top-down and bottom-up community regulation in marine rocky intertidal habitats. J Exp Mar Biol Ecol 250:257-289

Miner BG, Sultan SE, Morgan SG, Padilla DK, Relyea RA (2005) Ecological consequences of phenotypic plasticity. Trends Ecol Evol 20(12):685-692

Miron G, Boudreau B, Bourget E (1999) Intertidal barnacle distribution: a case study using multiple working hypotheses. Mar Ecol Prog Ser 189:205-219

Moran AL (1999) Size and performance of juvenile marine invertebrates: potential contrasts between intertidal and subtidal benthic habitats. Amer Zool 39:304-312

Moran AL, Emlet RB (2001) Offspring size and hatchling performance of an intertidal gastropod under variable field conditions. Ecology 82:1597-1612

Navarrete SA, Broitman B, Wieters EA, Finke GR, Venegas RM, Sotomayor A (2002)

Ohgushi T, Schmitz O, Holt RD (2012) Trait-mediated indirect interactions. Cambridge University Press

Pechenik JA (2006) Larval experience and latent effects-metamorphosis is not a new beginning. J Integr Comp Biol 47:1-11

Pechenik JA, Rittschof D, Schmidt AR (1993) Influence of delayed metamorphosis on survival and growth of juvenile barnacles Balanus amphitrite. Mar Biol 115:287-294

Pechenik JA, Wendt DE, Jarrett JN (1998) Metamorphosis is not a new beginning. BioScience 48:901-910

Phillips NE (2002) Effects of nutrition-mediated larval condition on juvenile performance in a marine mussel. Ecology 83:2562-2574 
Pinheiro J, Bates D, DebRoy S, Sarkar D, R Core Team (2015) nlme: Linear and nonlinear

657 mixed effects models. $\mathrm{R}$ package version 3.1-122, $\underline{\text { http://CRAN.R- }}$ project.org/package $=$ nlme

659

660

661

662

663

664

665

666

667

668

669

670

671

672

673

674

675

676

677

678

679

680

Prout T, McChesney F (1985) Competition among immatures affects their adult fertility: population dynamics. Am Nat 126(4):521-558

Rainbow PS, Walker G (1977) The functional morphology of the alimentary tract of barnacles (Cirripedia: Thoracica). J Exp Mar Biol Ecol 28(2):183-206

Roughgarden J, Gaines S, Possingham H (1988) Recruitment dynamics in complex life cycles. Science 241:1460-1466

Schmitz OJ, Adler FR, Agrawal AA (2003) Linking Individual-Scale Trait Plasticity to Community Dynamics. Ecology 84(5):1081-1082

Shima JS, Swearer SE (2009) Larval quality is shaped by matrix effects: implications for connectivity in a marine metapopulation. Ecology 90(5):1255-1267

Spight TM (1976). Ecology of hatching size for marine snails. Oecologia 24:283-294

Svensson CJ, et al (2004) Models of open populations with density dependent recruitment in stochastic environments: an application to the barnacle Semibalanus balanoides. Mar Ecol Prog Ser 275:185-197

Tamate T, Maekawa K (2000) Interpopulation variation in reproductive traits of female masu salmon, Oncorhynchus masou. Oikos 90(2):209-218

Thiyagarajan V, Harder T, Qian P-Y (2002a). Effect of the physiological condition of cyprids and laboratory-mimicked conditions on the metamorphic success of Balanus amphitrite Darwin (Cirripedia: Thoracica). J Exp Mar Biol Ecol 274:65-74

Thiyagarajan V, Harder T, Qian P-Y (2002b). Relationship between cyprid energy reserves and metamorphosis in the barnacle Balanus amphitrite Darwin (Cirripedia; Thoracica). J Exp Mar Biol Ecol 280:79-93 
681 Thiyagarajan V, Harder T, Qiu J W, Qian P-Y (2003a) Effects of TAG/DNA ratio and age of 682 cyprids on post-metamorphic growth and survival in the barnacle Balanus amphitrite. J $683 \quad$ Mar Biol Ass UK 83:83-88

684 Thiyagarajan V, Harder T, Qiu J W, Qian P-Y (2003b) Energy content at metamorphosis and 685 growth rate of the juvenile barnacle Balanus amphitrite. Mar Biol143:543-554

686 Thorson G (1950) Reproductive and larval ecology of bottom marine invertebrates. Biol Revs 687 $25: 1-45$

688

Tremblay R, Olivier F, Bourget E, Rittschof D (2007) Physiological condition of Balanus amphitrite cyprid larvae determines habitat selection success. Mar Ecol Prog Ser 340:1-8

Underwood AJ, Keough MJ (2001) Supply-side ecology: the nature and consequences of 691 variations in recruitment of intertidal organisms. In: Burtness MD et al. (eds.) Marine community Ecology. Sinauer Associates, pp 183-200

693

Van Allen BG, Rudolf VHW (2013) Ghosts of habitats past: environmental carry-over effects drive population dynamics in novel habitat. Am Nat 181(5):596-608

Wendt DE (1998) Effect of larval swimming duration on growth and reproduction of Bugula 696 neritina (Bryozoa) under field conditions. Biol. Bull.195:126-35

697

698

Werner EE, Peacor SD (2003) A review of trait-mediated indirect interactions in ecological communities. Ecology 84(5):1083-1100

West TL, Costlow JD (1987) Size regulation in larvae of the crustacean Balanus eburneus (Cirripedia: Thoracica). Mar Biol 96:47-58 


\section{TABLES}

Table 1. Austrominius modestus. Two-way nested ANOVAs evaluating the effect of food concentration and replicate vessel (nested in food concentration) on body length of swimming cyprids for two different experiments. Significant effects are in bold. The F statistics of the food effect was calculated using the MS of the Vessel effect as denominator; the corresponding df was used for the calculation of the $\mathrm{p}$ value.

\begin{tabular}{lrrrr}
\hline & \multicolumn{4}{c}{ Experiment 1 } \\
\cline { 2 - 5 } Food & df & \multicolumn{1}{c}{ MS } & \multicolumn{1}{c}{ F } & \multicolumn{1}{c}{ p } \\
Vessel (F) & 2 & 5003 & 17.0 & $<\mathbf{0 . 0 0 0 1}$ \\
Error & 15 & 294 & 0.5 & 0.92 \\
\multicolumn{5}{c}{ Experiment 2 } \\
\hline & 162 & 556 & & \\
\cline { 2 - 5 } & \multicolumn{5}{c}{ df } & \multicolumn{1}{c}{ M } & \multicolumn{1}{c}{ p } \\
\hline Food & 2 & 48889 & 47.4 & $<\mathbf{0 . 0 0 0 1}$ \\
Vessel (F) & 14 & 1032 & 1.8 & $\mathbf{0 . 0 3 8}$ \\
Error & 323 & 574 & & \\
\hline
\end{tabular}

Table 2. Austrominius modestus. One-way ANOVAs evaluating the effect of food concentration on dry mass (DW) and elemental composition (\% $\mathrm{C}$ and $\% \mathrm{~N})$ of swimming cyprids for Experiment 2 (degrees of freedom of food and error were 2 and 13 respectively). Significant effects are in bold.

\begin{tabular}{lcccccc}
\hline & \multicolumn{3}{c}{ Dry mass (DW) } & \multicolumn{3}{c}{ C:N ratio } \\
\cline { 2 - 7 } & $\mathrm{MS}$ & $\mathrm{F}$ & $\mathrm{p}$ & $\mathrm{MS}$ & $\mathrm{F}$ & $\mathrm{p}$ \\
\hline Food & 4.20 & 13.87 & $\mathbf{0 . 0 0 0 6}$ & 3.10 & 13.50 & $\mathbf{0 . 0 0 0 7}$ \\
Error & 0.30 & & & 0.23 & & \\
\hline & \multicolumn{3}{c}{$\mathrm{C}(\%)$} \\
& \multicolumn{3}{c}{$\mathrm{F}$} & & $\mathrm{N}(\%)$ & \\
\cline { 2 - 7 } & $\mathrm{MS}$ & $\mathrm{F}$ & $\mathrm{p}$ & $\mathrm{MS}$ & $\mathrm{F}$ & $\mathrm{p}$ \\
\hline Food & 27.46 & 7.18 & $\mathbf{0 . 0 0 8}$ & 1.57 & 5.27 & $\mathbf{0 . 0 2 1}$ \\
Error & 3.83 & & & 0.30 & & \\
\hline
\end{tabular}


Table 3. Austrominius modestus. Two-way ANOVAs evaluating the effect of food concentration on size of metamorphs (measured as basal and operculum length) out-planted at different intertidal levels during two different experiments. Significant effects are in bold.

\begin{tabular}{|c|c|c|c|c|c|c|c|}
\hline \multirow{2}{*}{ Experiment 1} & \multirow[b]{2}{*}{ df } & \multicolumn{3}{|c|}{ Basal length } & \multicolumn{3}{|c|}{ Operculum length } \\
\hline & & MS & $\mathrm{F}$ & $\mathrm{p}$ & MS & $\mathrm{F}$ & $\mathrm{p}$ \\
\hline Intertidal level & 1 & 235 & 0.18 & 0.68 & 1816 & 1.52 & 0.23 \\
\hline Food & 2 & 37029 & 27.67 & $<0.0001$ & 8179 & 6.83 & 0.004 \\
\hline F x I & 2 & 395 & 0.29 & 0.75 & 340 & 0.28 & 0.76 \\
\hline Error & 27 & 1338 & & & 1198 & & \\
\hline \multirow{2}{*}{ Experiment 2} & \multirow[b]{2}{*}{ df } & \multicolumn{3}{|c|}{ Basal length } & \multicolumn{3}{|c|}{ Operculum length } \\
\hline & & MS & $\mathrm{F}$ & $\mathrm{p}$ & MS & $\mathrm{F}$ & $\mathrm{p}$ \\
\hline Intertidal level & 1 & 599 & 0.31 & 0.58 & 673 & 0.62 & 0.44 \\
\hline Food & 2 & 10010 & 5.17 & 0.012 & 3769 & 3.50 & 0.043 \\
\hline $\mathrm{F} \times \mathrm{I}$ & 2 & 1381 & 0.71 & 0.50 & 301 & 0.28 & 0.76 \\
\hline Error & 30 & 1935 & & & 1078 & & \\
\hline
\end{tabular}

Table 4. Austrominius modestus. Three way repeated measures ANOVAs evaluating the effect of food concentration, intertidal level and time on cumulative barnacle survival for two different experiments. Significant effects are in bold.

\begin{tabular}{lrlrrrrrr}
\hline & \multicolumn{4}{c}{ Experiment 1 } & \multicolumn{4}{c}{ Experiment 2 } \\
\cline { 2 - 9 } & \multicolumn{1}{c}{ df } & MS & \multicolumn{1}{c}{ F } & \multicolumn{1}{c}{ p } & \multicolumn{1}{c}{ df } & \multicolumn{1}{c}{ MS } & F & \multicolumn{1}{c}{ p } \\
\hline Food & 2 & 0.153 & 2.28 & 0.123 & 2 & 0.752 & 5.84 & $\mathbf{0 . 0 0 8 2}$ \\
Intertidal level & 1 & 1.271 & 18.93 & $\mathbf{< 0 . 0 0 1}$ & 1 & 0.003 & 0.02 & 0.88 \\
F x I & 2 & 0.259 & 4.81 & $\mathbf{0 . 0 3 5}$ & 2 & 0.05 & 0.41 & 0.67 \\
Error & 25 & 0.067 & & & 25 & 0.129 & & \\
Time & 5 & 0.282 & 57.45 & $\mathbf{< 0 . 0 0 0 1}$ & 5 & 0.665 & 153.96 & $<\mathbf{0 . 0 0 0 1}$ \\
T x F & 10 & 0.004 & 1.315 & 0.52 & 10 & 0.007 & 1.65 & 0.10 \\
T x I & 5 & 0.012 & 4.035 & $\mathbf{0 . 0 3 4}$ & 5 & 0.011 & 2.67 & $\mathbf{0 . 0 2 5}$ \\
T x F x I & 10 & 0.007 & 1.94 & 0.12 & 10 & 0.004 & 0.95 & 0.49 \\
Error & 125 & 0.004 & & & 125 & 0.004 & & \\
\hline
\end{tabular}


Table 5. Austrominius modestus. Generalised Linear Models (GzLM) evaluating the effect of food concentration, intertidal level and time on barnacle growth (basal and operculum length) for two different experiments. Significant effects are in bold.

\begin{tabular}{|c|c|c|c|c|c|}
\hline \multirow{2}{*}{ Experiment 1} & \multirow[b]{2}{*}{ df } & \multicolumn{2}{|c|}{ Basal length } & \multicolumn{2}{|c|}{ Operculum length } \\
\hline & & $\chi^{2}$ & $\mathrm{p}$ & $\chi^{2}$ & $\mathrm{p}$ \\
\hline Intertidal level & 1 & 16.78 & $<0.0001$ & 17.79 & $<0.0001$ \\
\hline Food & 2 & 0.57 & 0.75 & 1.14 & 0.56 \\
\hline Time & 4 & 404.93 & $<0.0001$ & 375.80 & $<0.0001$ \\
\hline I x F & 2 & 9.92 & 0.007 & 8.69 & 0.013 \\
\hline $\mathrm{S} \times \mathrm{T}$ & 4 & 13.88 & 0.008 & 7.87 & 0.096 \\
\hline $\mathrm{F} \times \mathrm{T}$ & 8 & 2.64 & 0.95 & 6.07 & 0.64 \\
\hline $\mathrm{I} \times \mathrm{F} \times \mathrm{T}$ & 8 & 4.06 & 0.85 & 9.44 & 0.31 \\
\hline \multirow{2}{*}{ Experiment 2} & \multirow[b]{2}{*}{ df } & \multicolumn{2}{|c|}{ Basal length } & \multicolumn{2}{|c|}{ Operculum length } \\
\hline & & $\chi^{2}$ & $\mathrm{p}$ & $\chi^{2}$ & $\mathrm{p}$ \\
\hline Intertidal level & 1 & 7.59 & 0.006 & 7.46 & 0.006 \\
\hline Food & 2 & 1.84 & 0.40 & 2.95 & 0.23 \\
\hline Time & 5 & 613.94 & $<0.0001$ & 562.78 & 0.0001 \\
\hline I x F & 2 & 1.85 & 0.40 & 0.45 & 0.80 \\
\hline I x T & 5 & 29.37 & $<0.0001$ & 28.09 & $<0.0001$ \\
\hline $\mathrm{F} \times \mathrm{T}$ & 10 & 27.05 & 0.0026 & 19.25 & $\mathbf{0 . 0 3 7}$ \\
\hline I x F x T & 10 & 3.09 & 0.98 & 2.24 & 0.99 \\
\hline
\end{tabular}




\section{FIGURE LEGENDS}

Figure 1. Austrominius modestus. Effect of larval food concentration on body size of swimming cyprids. (a) Experiment 1. (b) Experiment 2. Food concentration: low (open bars), medium (striped bars), high (closed bars). Different letters indicate significant differences between treatments after SNK posthoc test; error bars represent standard errors among replicate vessels.

Figure 2. Austrominius modestus. Effect of larval food concentration on dry mass and elemental composition ( $\mathrm{C}$ and $\mathrm{N}$ content) of swimming cyprids. (a) Dry mass. (b) \% Carbon. (c) \% Nitrogen. (d) C:N ratio. Food concentration: low (open bars), medium (striped bars), high (closed bars). Symbols as in Fig. 1.

Figure 3. Austrominius modestus. Effect of larval food concentration on body size (basal and operculum length) of out-planted metamorphs at the time of out-planting (day 0). (a) Experiment 1: basal length. (b) Experiment 2: basal length. (c) Experiment 1: operculum length. (d) Experiment 2: operculum length. Intertidal level: low (open bars), high (closed bars). Different letters indicate significant differences between treatments after SNK posthoc test; error bars represent standard errors among replicate vessels. Note that no differences between intertidal levels are presented showing that the sizes at metamorphosis were evenly distributed among intertidal levels.

Figure 4. Austrominius modestus. Effect of larval food concentration and intertidal level on survival of settlers through time. (a) Experiment 1: low intertidal. (b) Experiment 1: high intertidal. (c) Experiment 2: low intertidal. (d) Experiment 2: high intertidal. Food concentration: LF: low (open circle), MF: medium (closed square), HF: high (closed triangle). Error bars represent standard errors among replicate vessels. For Experiment 1, SNK posthoc tests were run for week, food and intertidal level combinations. Different letters indicate significant differences each week among food treatments; n.s. indicates no significant difference. For Experiment 2, a SNK posthoc test was run after a main food effect (interactions were not significant), different letters (at the end) indicate overall differences between food treatments.

Figure 5. Austrominius modestus. Effect of larval food concentration and intertidal level on growth (basal length) of settlers through time. (a) Experiment 1: low intertidal. (b) Experiment 1: high intertidal. (c) Experiment 2: low intertidal. (d) Experiment 2: high intertidal. Food concentration: LF: low (open circle), MF: medium (closed square), HF: high 
(closed triangle). Error bars represent standard errors among replicate vessels. Different letters indicate significant overall differences among food treatments after 10 weeks after SNK posthoc test; n.s. indicates no significant difference.

Supplementary figure. Austrominius modestus. Standardised average (X) effect of food concentration on cyprid length, metamorph basal length, and survival after 2 weeks. For each variable, the averages were standardised separately following the equation: $\mathbf{X}=\left(\dot{\mathbf{X}}_{\mathbf{i}}-\ddot{\mathbf{X}}\right) / \mathbf{S}$ with $\dot{X}_{\mathrm{i}}=$ mean value for each treatment $\left(\dot{\mathrm{X}}_{1}, \dot{\mathrm{X}}_{2}, \dot{\mathrm{X}}_{3}\right), \ddot{\mathrm{X}}=$ overall mean value $\left(\dot{\mathrm{X}}_{1}, \dot{\mathrm{X}}_{2}, \dot{\mathrm{X}}_{3}\right), \mathrm{S}$ = standard deviation $\left(\dot{X}_{1}, \dot{X}_{2}, \dot{X}_{3}\right)$ and plotted using the same scale. Food concentration: LF: low (open bars), MF: medium (striped bars), HF: high (closed bars). The survival data from Experiment 1 were standardised only from low intertidal since there was no effect of food on the high intertidal. For Experiment 2 survival data from both intertidal levels were pooled since both levels showed the same effects of food concentration. 

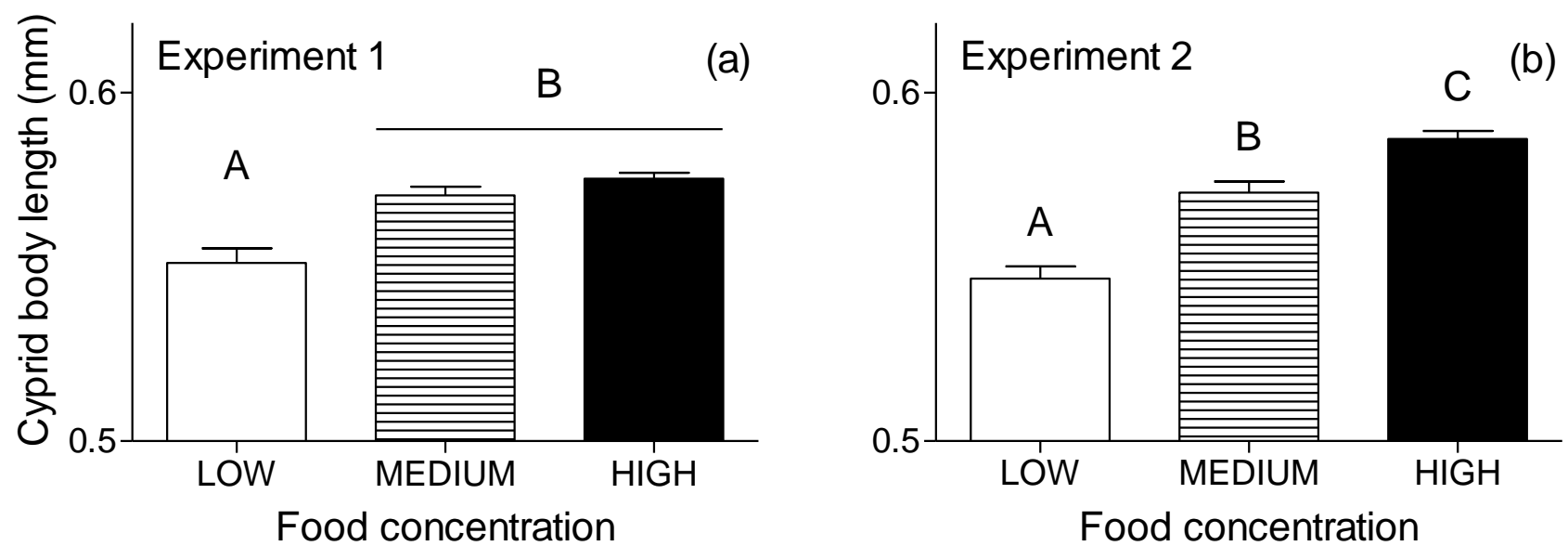

Figure 1 


\section{Experiment 2}
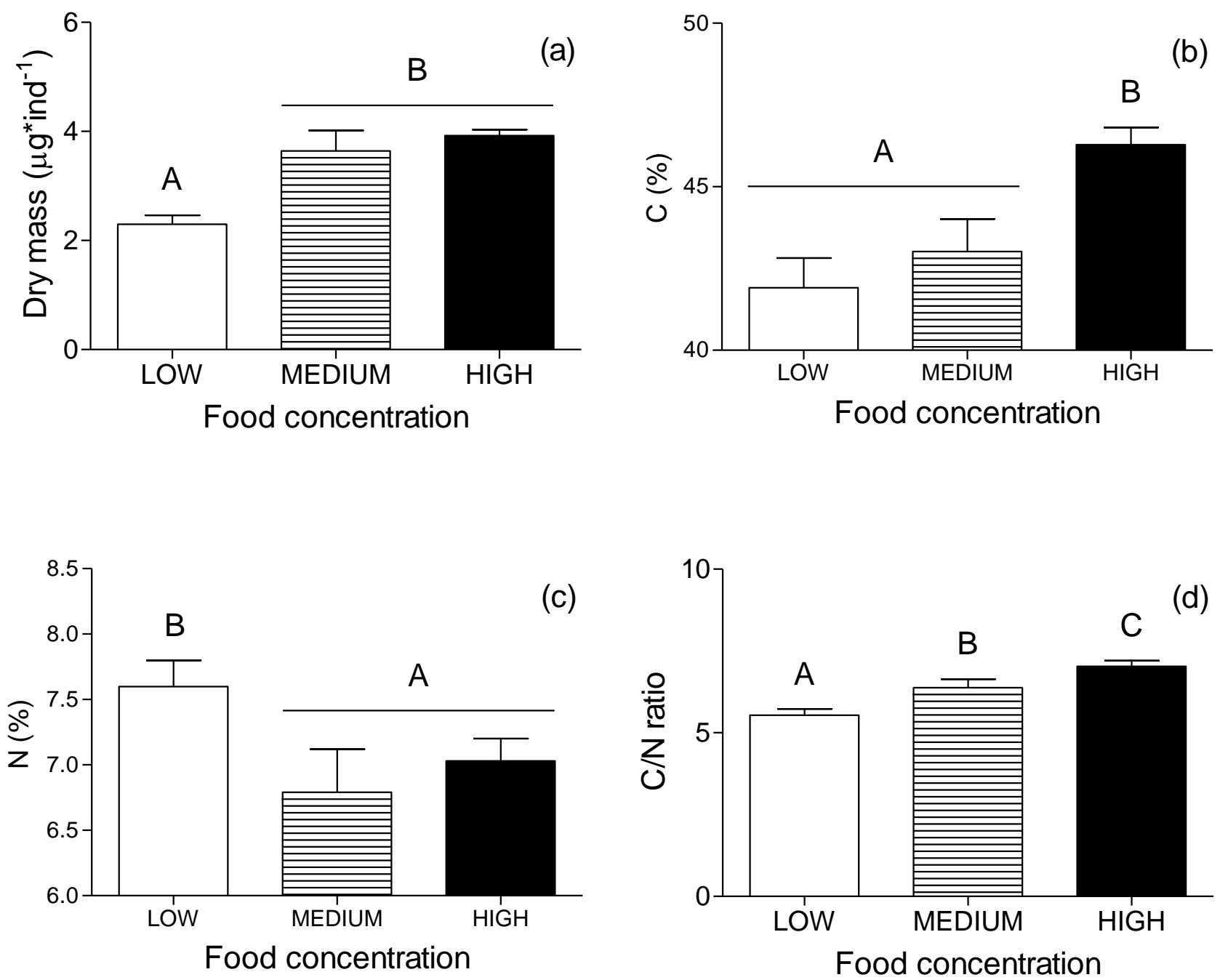

Figure 2 
Experiment 1

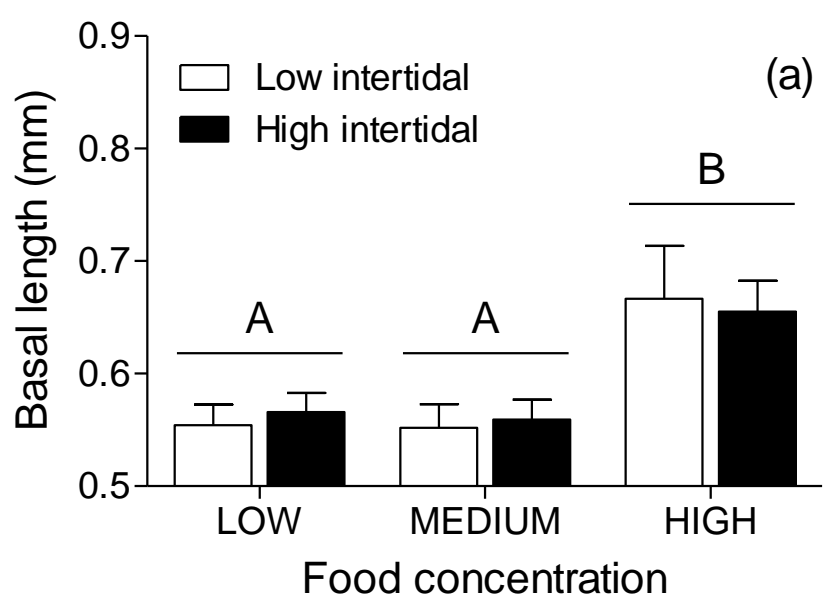

Experiment 1

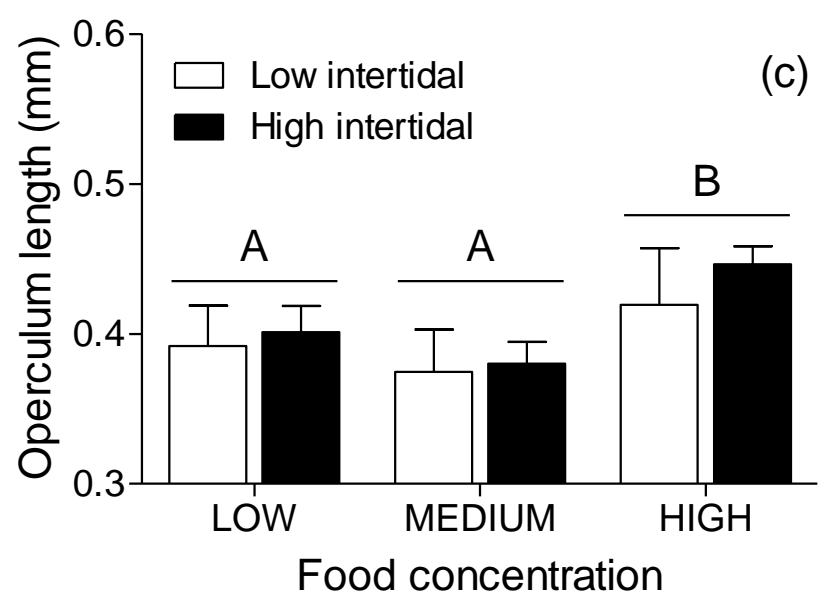

Experiment 2

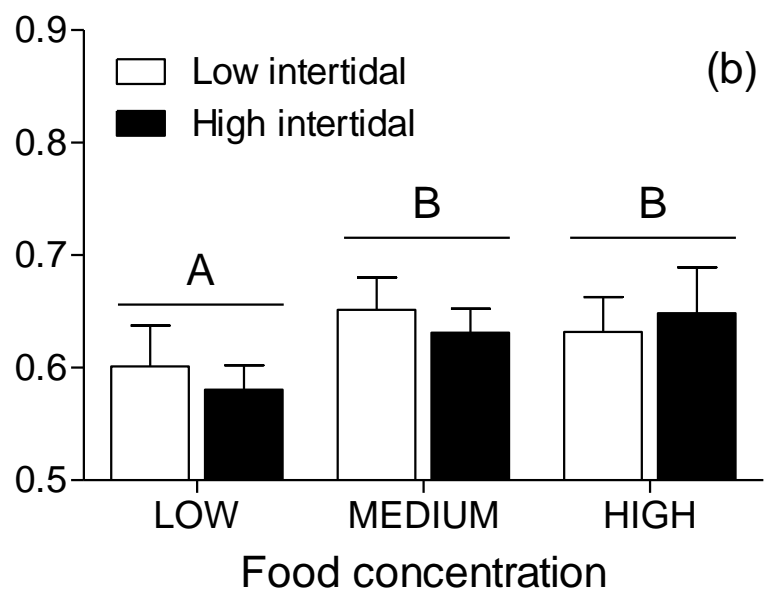

Experiment 2

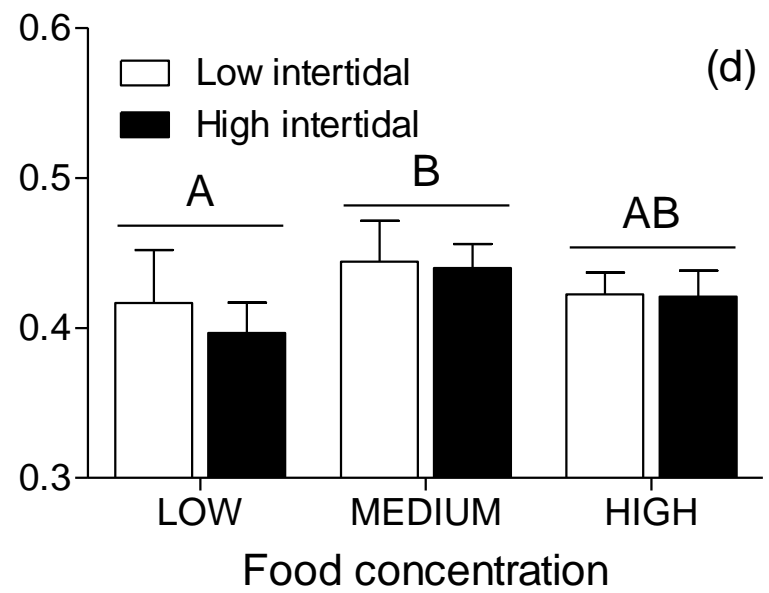




\section{Experiment 1}
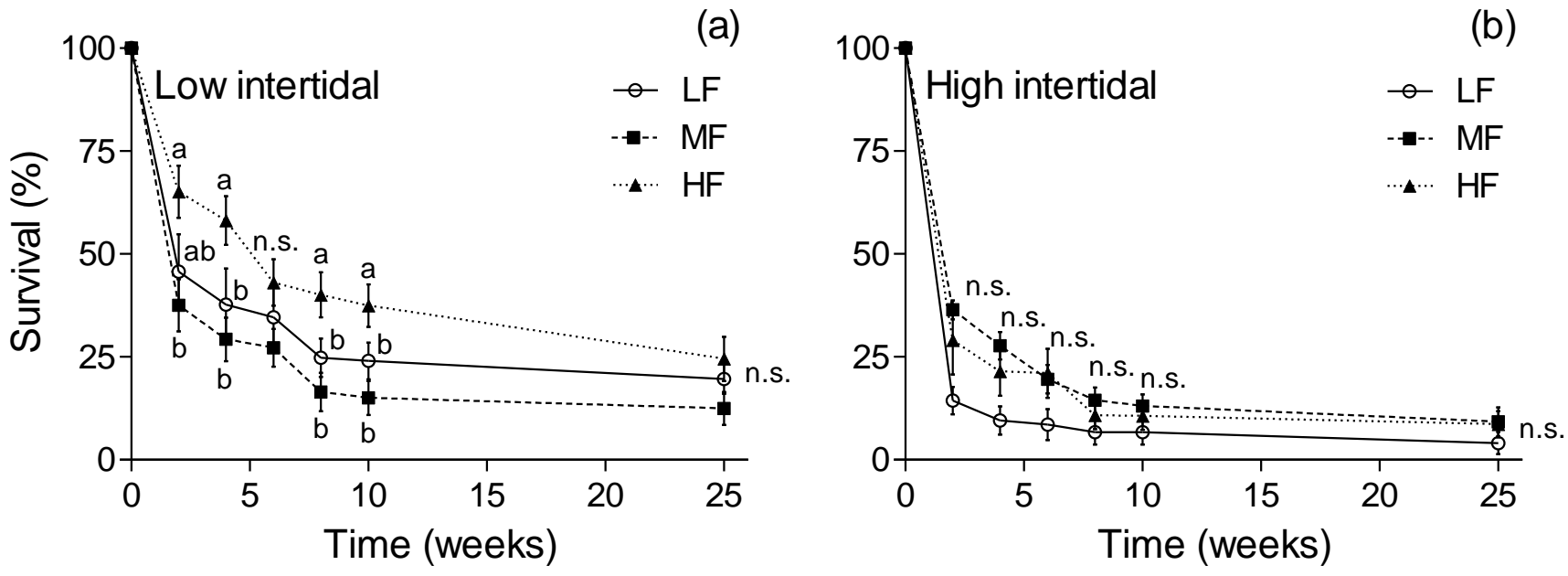

\section{Experiment 2}
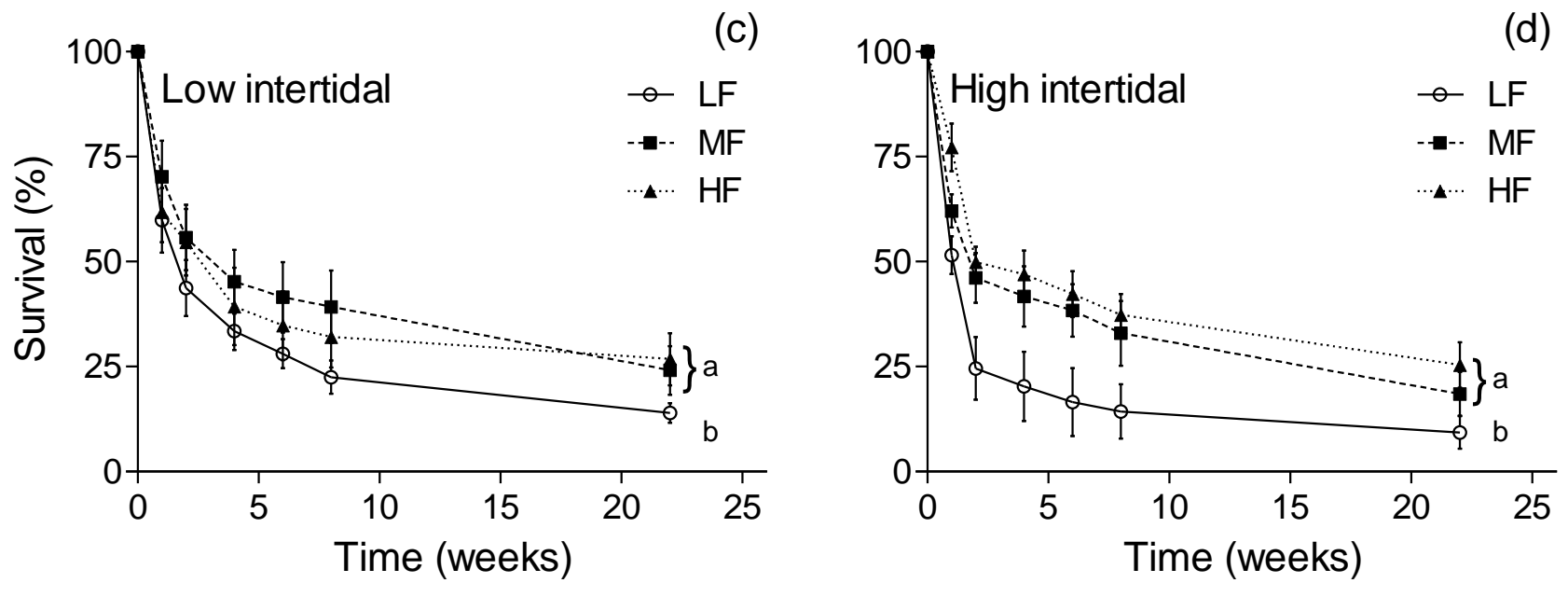

Figure 4 


\section{Experiment 1}
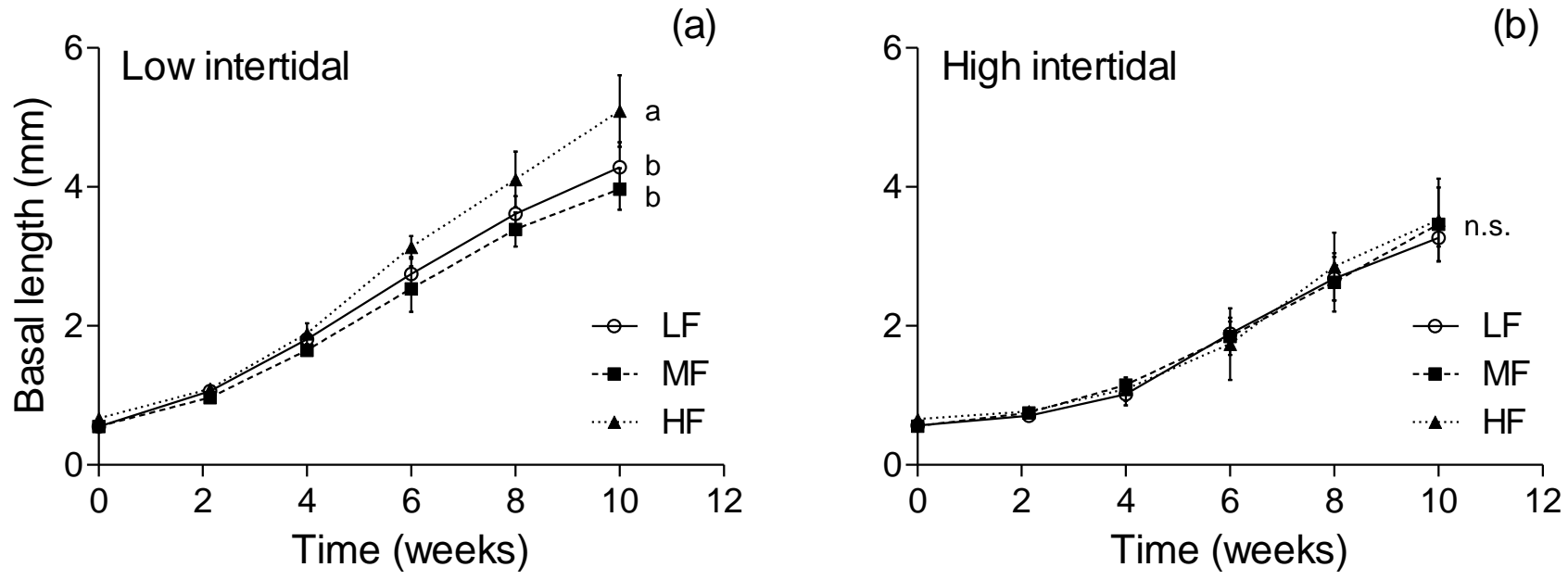

\section{Experiment 2}
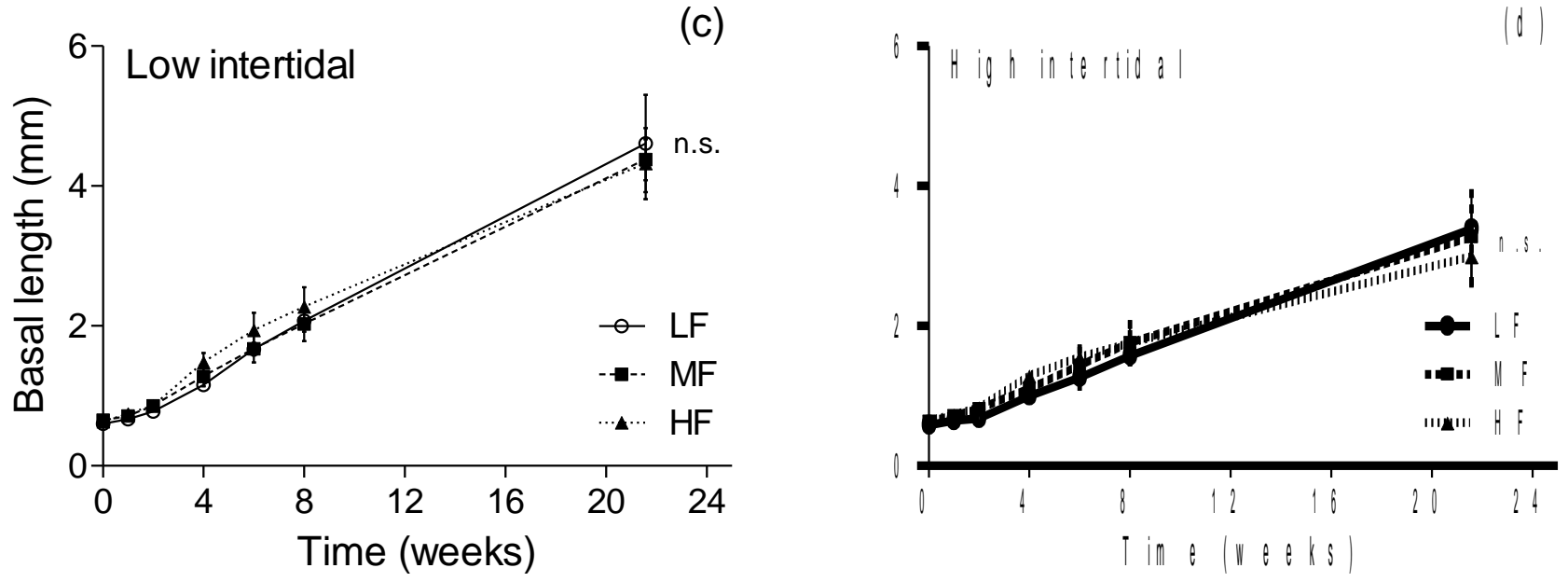

Figure 5 

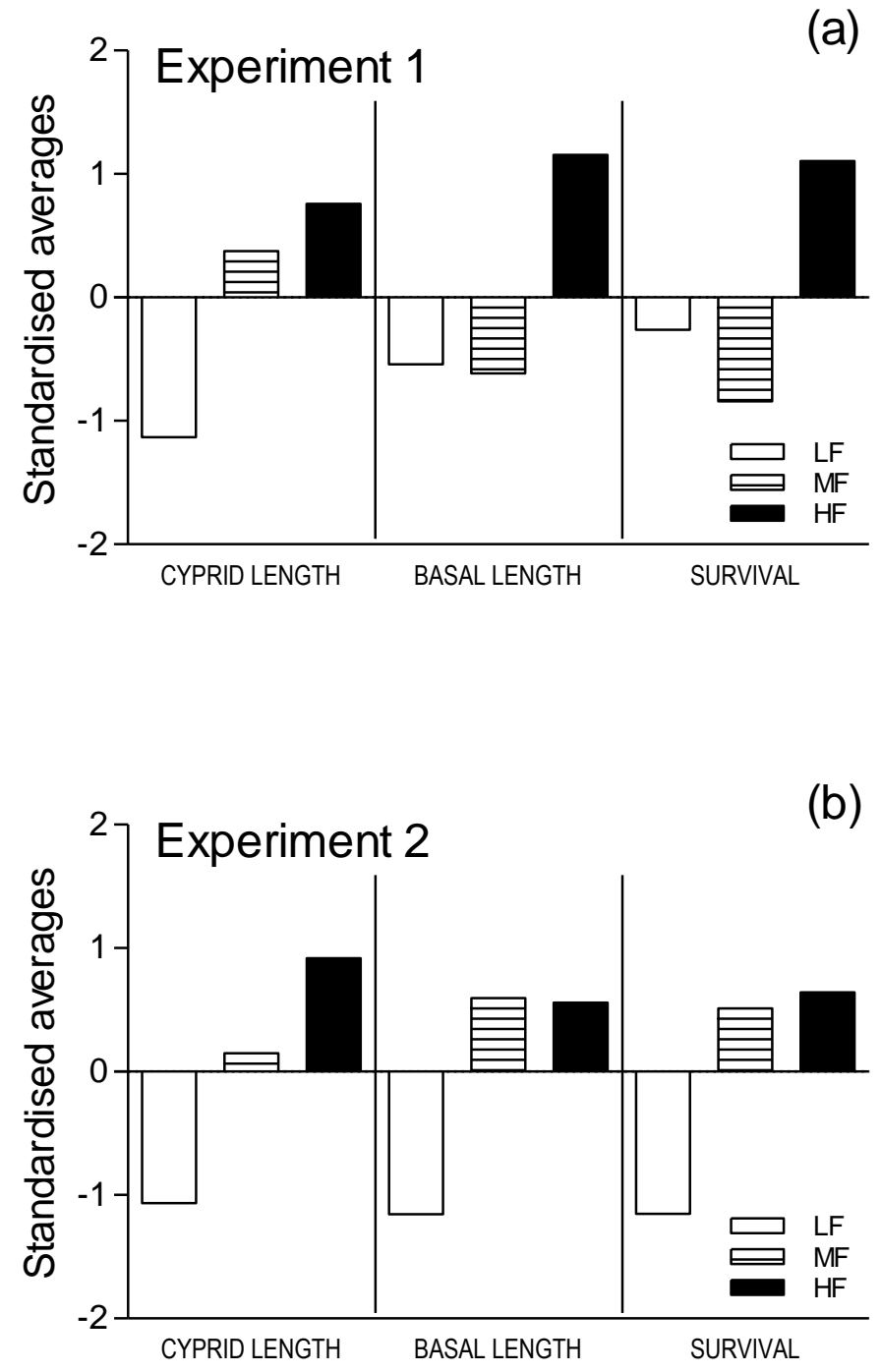